\title{
China's uncertain demographic present and future
}

\author{
Wolfgang Lutz, Sergei Scherbov, Gui Ying Cao, Qiang Ren and \\ Xiaoying Zheng*
}

\begin{abstract}
This paper applies methods of probabilistic population forecasting to assess the range of uncertainty of China's future population trends. Unlike previous applications of probabilistic population projections that consider stochastic future fertility, mortality and migration, this paper will also account for the significant uncertainty of China's current fertility level (with published figures ranging from 1.2 to 2.3 ) and the related uncertainties about the sex ratio at birth (with estimates from 1.06 to above 1.2) and the size of the youngest cohorts in the 2000 census. The model applied in this paper will be based on assumed uncertainty ranges for current conditions, in addition to the probabilistic treatment of future trends. Given the sheer size of China's population, these significant uncertainties about current conditions are of high importance not only for the future population of China but also for considerations on a global scale.
\end{abstract}

\section{Introduction}

Information about population trends at the national level is a key prerequisite for policy planning in a large array of topic ranging from social security and health provision to the schooling system, labour markets, urban planning and infrastructure to national defence. This is why virtually all countries in the world collect population data through censuses, surveys or from existing registers and use population projections as input to the planning in these fields. For this

\footnotetext{
* Wolfgang Lutz (author for correspondence), World Population Program, International Institute for Applied Systems Analysis (IIASA), Schlossplatz 1, 2361 Laxenburg, Austria and Vienna Institute of Demography, Austrian Academy of Sciences, Vienna. Email: lutz@iiasa.ac.at

Sergei Scherbov, Vienna Institute of Demography, Austrian Academy of Sciences, Vienna and World Population Program, International Institute for Applied Systems Analysis (IIASA), Laxenburg, Austria.

Gui Ying Cao, Forestry Program, International Institute for Applied Systems Analysis (IIASA), Laxenburg, Austria.

Qiang Ren, Institute of Population Research, Peking University, Beijing, PR China.

Xiaoying Zheng, Institute of Population Research/WHO Collaborating Center on Reproductive Health and Population Science, Peking University, China Population Association. Email: xzheng@pku.edu.cn
} 
purpose it is evident that the demographic information provided should be as accurate as possible. However, it is not always possible to get completely accurate information. As to the future this is due to some extent to the inherent indeterminacy of fertility, mortality and migration paths and our limited knowledge about the forces driving these trends. In many countries we also lack accurate information about current conditions and have no easy way to go and improve the accuracy of this information. China is in some respects one of these countries and the uncertainty of current and future demographic conditions in China is the topic of this paper.

Uncertainty in future demographic trends is an issue for every country but in the case of China it is also a global issue. If one believes that global population figures are of more than purely academic interest and that they matter for issues as diverse as global carbon dioxide emissions or global labour markets under rapidly globalising trade regimes then trends in China's population are directly relevant to the rest of the world. More than with any other country, the sheer size of China's population-which constitutes around $20 \%$ of the world's totalmakes it a key determinant of global population trends. In this light it is surprising how much uncertainty exists about the current demographic conditions in the world's biggest country. Recently published figures of China's total fertility rate around 2000 range from 1.22 (NSB 2002a, 2000b) to 2.3 (Liang 2003) - a remarkable difference, especially seen on a relative scale (a factor of 1.89). There are probably few countries in the world where estimates about current fertility rates differ by such a factor.

Because of China's weight in the world population, the estimates of the current global fertility rates are significantly affected by this uncertainty, as are projections for the world population. If fertility in China were currently below 1.5 , as many authors estimate and the UN publishes in its 2004 fertility data sheet (UN 2005), instead of the 1.85 assumed by the $\mathrm{UN}$ in its recent long-range projections (UN 2004), this would influence the assumed fertility level over the coming decades and result in markedly lower projected rates of population growth (shrinking later in the century) both in China and the world.

Fertility is not the only uncertain demographic condition in China today. Estimates for the sex ratio at birth range from 113 (Wang 2003) to 123 (Ma 2004). This is a remarkable difference that will significantly influence the future proportion of men to women in the adult population and hence population dynamics.

Important uncertainty also exists about the size of the youngest age group. The size of the age group 0-4 in 2000 is given as 71 million in the census, but is estimated to be 86 million (Zhang et al. 2004). The difference of 15 million in just one age group is not only daunting in absolute numbers but also represents a sizeable relative difference of $20 \%$.

The recently released new results of the 2005 National One Percent Population Sample Survey (NBS 2007) fit very well into this spectrum of different published figures. It gives a TFR of 1.33 for 2005 and a sex ratio at birth 
of 120.5. Since so far no studies have been published on the accuracy of these newest data, we cannot view them as information that helps to narrow the uncertainty range yet. Instead we will treat them as one more published figure in line with the many others discussed in this paper.

This paper will first discuss how demographers have traditionally dealt with the issue of uncertainty about current conditions - mostly by ignoring that uncertainty if accuracy could not be further improved-before moving on to future trends and the options for systematically including quantitative information about this uncertainty in population estimates and projections. We then discuss the wide range of published data about China's current fertility level, sex ratio and the size of the younger population. Next, we consider the range of future fertility (including the sex ratio), mortality and migration that should be reflected in our projections prior to carrying out probabilistic projections which cover the uncertainty of current conditions as well as future trends. The final sections will present and discuss the results and draw some conclusions.

\section{How demographers deal with uncertainty about current conditions and future trends}

To be uncertain about the exact size and age structure of a population or the current level of fertility, mortality and migration, is nothing new for demographers. Almost all empirical information, be it from censuses, vital registration or surveys, is imperfect, but the degree of imperfection varies significantly from one setting to another. The typical response to such imperfection on a minor scale usually is to settle for one number which is then used in further analysis without continuing to worry about the uncertainties associated. In those rare cases where these published numbers are publicly challenged or when demographers themselves feel that the degree of imperfection of the given empirical information is intolerable as a basis for analysis and interpretation, they tend to have two alternative strategies: either to go out into the field and collect new information or to use various kinds of statistical techniques so as to improve the given data. Sometimes both methods are combined, but the goal is typically the same: to come up with one point estimate that should be as close as possible to the real world. This is, of course, a meaningful strategy and it is the task of scientific analysis to reduce uncertainty as much as possible. However, what is possible under specific conditions is not always sufficient to come up with a reliable estimate. In some countries there simply have not been any reliable censuses or surveys recently and it is thus beyond the power of the analysing demographer to collect better empirical information. In such instances point estimates are associated with large uncertainties. In international comparisons, these point estimates typically go into tables where, e.g., the highly reliable estimate for life expectancy derived from a Nordic population register 
stands next to the estimated figure for some African countries where the level of mortality can only be known in a very broad range.

Typically, the user of such internationally comparative tables is not given any indication about differential uncertainties surrounding these point estimates. But even if the researchers working with the data are painfully aware of the uncertainty of a given point estimate, they mostly see no other choice than to base their projections and other analyses on this uncertain point estimate of demographic conditions at a given time. In common practice it is considered still better to have an imperfect figure that roughly characterises the actual situation than to have no figure at all.

Unlike some other disciplines, there is little tradition in demography to process fuzzy information and still be able to maintain the information about the uncertainty of any given indicator in the subsequent steps of the analysis. In this paper we propose to do so by expanding the methods of probabilistic population projections to also include uncertainty distributions of the starting conditions of these very projections.

The field of probabilistic population projections has recently seen a dynamic development. In 2004 the International Statistical Review published a special issue on how to deal with uncertainty in population forecasting (Lutz and Goldstein 2004). It presents a state-of-the-art summary of different dimensions of, and different approaches to, probabilistic population projections. It also shows how dynamically the field has been expanding since Frontiers of Population Forecasting (Lutz, Vaupel and Ahlburg 1999) and the National Research Council (2000) report on population projections were written. There is no space here to review this field of studies. Suffice it to note that originally there were three rather different approaches, which have recently seen some convergence. The first one is based on the analysis of errors in past population projections and the assumption that future errors will be similar to past errors (Alho 1997; Keilman 1999; Lee 1999). The second approach is largely based on time series analysis and produces stochastic projections on the assumption of structural continuity and constant variability (Lee 1993; Lee and Tuljapurkar 1994). The third approach largely rests on subjective probability distributions produced by experts in the process of an argument-based discussion process about the likely future range of uncertainty in fertility, mortality and migration (Lutz, Sanderson and Scherbov 1997, 1999). While the first two approaches usually distinguish between assumptions on the trend (which is mostly based on expert opinion) and the variance (which is derived from past errors or time series), under the third approach, trend and variance are assumed jointly as being part of the same uncertain process.

There is considerable debate at the moment about which of the three approaches is most appropriate under different conditions of data availability, at various stages in the process of demographic transition and in other contextual settings. This discussion, which seems to move in the direction of combining elements from the different approaches and is summarised in Lutz and Goldstein (2004), has not yet resulted in a broad methodological consensus and is unlikely 
to do so in the near future because of the great variety of conditions under which such projections are being produced. In the context of this study on China, it is important to note that the full range of options is not applicable to all countries. The use of past projection errors is only applicable to populations for which there are both a series of past projections and reliable empirical data for verification. The time series approach can only be pursued if sufficiently long, high-quality time series are available. These preconditions significantly limit the number of countries to which all three methods are applicable. As discussed in detail below, China clearly does not meet these preconditions.

Methodologically, this paper goes a step beyond previous probabilistic projections in applying the probabilistic approach not only to capture the future uncertainty but also to address the uncertainty about current conditions. In principle, these two kinds of uncertainty are of a different nature. While the future holds some inherent uncertainty that cannot be fully eliminated even with major efforts, the uncertainty about current conditions could at least theoretically be eliminated through better data collection. Since in practice this is often impossible or too expensive the bottom line in many cases is an uncertainty distribution about current conditions that is isomorphic to the one about future conditions.

In terms of methods to be used for this task the approaches other than subjective probabilities based on expert knowledge are not applicable. The time series approach depends on reliable empirical data by its very nature and is meaningless without them, hence, by definition it cannot be applied to uncertain empirical information. The approach of learning from past errors could theoretically be expanded to refer to errors about point estimates that have later been revised as better empirical information became available. But this would have to be based on the very strong assumption that there is a universal pattern of biases when producing point estimates under conditions of uncertainty about the real level of demographic indicators. There is no reason to assume that there is such a universal and predictable pattern of biases in estimating current fertility levels, sex ratios or age group sizes that would hold for all countries and times. Hence, the only alternative is to look carefully at what some of the best experts in the country under consideration and the entire scientific literature have to say in terms of different attempts to estimate current demographic conditions and then to infer an uncertainty distribution from this informed judgement.

\section{Uncertainty ranges of current demographic conditions in China}

\subsection{Current fertility level}

Table 1 gives a long list of more than 30 different figures for China's total fertility rate (TFR) around 2000 that have recently been published. The sheer number of 
these different values given for a situation in which only one number can be true gives an indication of the uncertainty as well as of the controversy surrounding the current fertility level in China. In this study we will restrict our consideration to published figures. The number of unpublished estimates produced by different institutions or individuals is probably much greater. These published figures of the total fertility rate in China in 2000 span a range from 1.22 (NSB 2002a, $2000 \mathrm{~b}$ ) to 2.3 (Liang 2003). All the other figures that were published and supported by at least a simple transparent rationale lie between these values but are clearly not evenly distributed.

To put things into a temporal perspective, Table 2 gives the time series for the TFR since the mid-1980s from five independent sources of data. These show considerable variation, but all give values of below 1.5 since the mid-1990s. There is, however, widespread agreement among experts that they all tend to be subject to underreporting of births, particularly in the years immediately preceding each census/survey. The critical question is what degree of underreporting should be assumed, and accordingly, what correction factors should be applied? This is where the alternative estimates for the TFR around 2000 differ.

There is no space here for a detailed discussion of the rationales and methods behind the individual figures. These are well documented in the studies themselves. For defining an uncertainty distribution of fertility around the year 2000, we considered two alternative approaches: (1) Simply give every study equal weight and calculate the mean and variance of the distribution of different figures, which then are used to define a normal distribution. (2) Try to exert some judgement about which studies are more authoritative than others and have the distribution informed by that choice. While the first rather mechanistic approach is intellectually unsatisfactory because it leaves no room for quality judgements, the second is in danger of being too dependent on our personal (possibly biased) judgement about quality. After extensive considerations and discussions (including those at a high level forum on low fertility in East Asia held in Beijing in May 2005), we reached a compromise between the two alternative approaches. It was decided to use the Retherford et al. (2005) estimate for the TFR of around 1.5 , based on a systematic application of the own-children method, as the median of a normal distribution which covers $95 \%$ in the range between 1.2 and 1.8 . This uncertainty range with a symmetric distribution around 1.5 found the broadest 
Table 1:

Different estimates of the total fertility rate for China in $\mathbf{2 0 0 0}$

\begin{tabular}{|c|c|c|}
\hline Source & TFR & Notes \\
\hline Wang (2003) & $\begin{array}{l}1.718(1) \\
1.703(2) \\
1.723(3)\end{array}$ & $\begin{array}{l}\text { (1) Uncorrected fertility pattern: calculation directly by age-specific } \\
\text { fertility rate of } 2000 \text { census without considering the underreporting } \\
\text { of children; (2) Adjustment by reconstructing the underreporting of } \\
\text { children: to keep age/parity-specific rate of } 2000 \text { census stable, } \\
\text { re-estimate the fertility pattern after reconstructing those children } \\
\text { who are underreported in the census; (3) Adjustment by fertility } \\
\text { pattern of the second child: due to the serious underreporting of the } \\
\text { second child, re-estimate the fertility pattern of the second child by } \\
\text { reconstructing those children who are underreported in the census. }\end{array}$ \\
\hline Liang (2003) & 2.3 & \\
\hline Yuan et al. (2003) & $\begin{array}{l}1.71(1) \\
1.78(2) \\
1.63(3)\end{array}$ & $\begin{array}{l}\text { (1) Calculation by National Statistical Yearbook; (2) Statistics of } \\
\text { State Family Planning Committee; (3) Using the surviving method } \\
\text { for children aged } 0-10 \text { years in } 2000 \text {, the number of births has been } \\
\text { estimated for each year assuming a life expectancy in } 1990 \text { of } \\
67.767 \text { for males and } 71.15 \text { for females, and in } 2000 \text { of } 69.54 \text { for } \\
\text { males and } 73.01 \text { for females. }\end{array}$ \\
\hline CPDRC (2003) & 1.80 & \\
\hline NSB (2002a, 2000b) & 1.22 & \\
\hline Zhang et al. (2004) & $\begin{array}{l}1.63(1) \\
2.0(2)\end{array}$ & $\begin{array}{l}\text { (1) Adjustment by the underreporting rate of } 18.94 \% \text { for } 0-9 \text { years } \\
\text { old; (2) Assuming the number of population aged } 10-19 \text { years old is } \\
\text { correct, the underreporting rate for children aged } 0-9 \text { years old is } \\
13.68 \% \text {, and the adjusted TFR is } 2.0 \text { assuming the underreporting } \\
\text { rate is the same between } 1990 \text { and } 2000 \text {. }\end{array}$ \\
\hline Zhai (2003) & 1.8 & \\
\hline Guo and Chen (2007) & 1.58 & Calculation by author eliminating tempo effects. \\
\hline $\begin{array}{l}\text { Zhang and Zhao } \\
\text { (2006); Zhang (2004) }\end{array}$ & $1.5-1.6$ & \\
\hline $\begin{array}{l}\text { Retherford et al. } \\
(2005)\end{array}$ & $\begin{array}{l}1.36(1) \\
1.38(2) \\
1.58(3) \\
\end{array}$ & $\begin{array}{l}\text { (1) Calculation by own-children method; (2) Calculation by birth } \\
\text { history reconstruction; (3) Adjustment by a factor from the } \\
\text { comparison between the } 1990 \text { and } 2000 \text { censuses. }\end{array}$ \\
\hline Ding (2003) & 1.35 & \\
\hline Scharping (2005) & 1.6 & $\begin{array}{l}\text { To use the educational statistics compared with the data from } \\
\text { National Population and Family Planning Committee and National } \\
\text { Statistic Bureau for an estimate of TFR. }\end{array}$ \\
\hline SFPC (2002) & 1.45 & \\
\hline Cai (2006) & $1.5-1.6$ & $\begin{array}{l}\text { To use Preston and Coale's variable-r method to assess the fertility } \\
\text { level in China by data from China's } 1990 \text { and } 2000 \text { censuses, and } \\
\text { annual population sample surveys. }\end{array}$ \\
\hline $\mathrm{Yu}(2002)$ & $\begin{array}{l}1.55(1) \\
1.32(2) \\
1.6- \\
1.8(3)\end{array}$ & $\begin{array}{l}\text { (1) Estimated by the number of population from } 2000 \text { census data; } \\
\text { (2) Estimated by the number of children from } 2000 \text { census data; (3) } \\
\text { Estimated by author. }\end{array}$ \\
\hline ESCAP (2002) & 1.8 & \\
\hline $\begin{array}{l}\text { U.S. Census Bureau } \\
(2004)\end{array}$ & 1.7 & \\
\hline Zhang and Cui (2003) & $\begin{array}{l}1.38(1) \\
1.63(2) \\
2.0(3) \\
1.8(4)\end{array}$ & $\begin{array}{l}\text { (1) Calculation using only the census long form; (2) Lower limit } \\
\text { value; (3) Upper limit value; (4) Author's estimated round value. }\end{array}$ \\
\hline SFPC (2001) & 1.8 & \\
\hline
\end{tabular}


consensus among the experts that were involved in the discussions. In the projections, the TFR value for 2000 (the starting year of the projections) was randomly chosen from this distribution for each of the 1,000 independent cohort component projection runs. This chosen level for fertility in 2000 then also serves as the base line fertility for the stochastic projections.

Table 2:

Total fertility rate for China since 1990

\begin{tabular}{|c|c|c|c|c|c|}
\hline Year & $\mathrm{NSB}^{1}$ & 1992 Survey $^{2}$ & 1997 Survey $^{3}$ & 2001 Survey $^{4}$ & 2000 Census $^{5}$ \\
\hline 1986 & 2.42 & 2.46 & 2.59 & & \\
\hline 1987 & 2.59 & 2.57 & 2.66 & & \\
\hline 1988 & 2.31 & 2.28 & 2.41 & & \\
\hline 1989 & 2.25 & 2.24 & 2.40 & & \\
\hline 1990 & 2.17 & 2.04 & 2.29 & 2.29 & 2.37 \\
\hline 1991 & 2.01 & 1.66 & 1.75 & 1.77 & 1.80 \\
\hline 1992 & 1.86 & 1.47 & 1.57 & 1.59 & 1.68 \\
\hline 1993 & 1.71 & & 1.51 & 1.52 & 1.57 \\
\hline 1994 & 1.56 & & 1.32 & 1.41 & 1.47 \\
\hline 1995 & 1.43 & & 1.33 & 1.45 & 1.48 \\
\hline 1996 & 1.55 & & 1.35 & 1.36 & 1.36 \\
\hline 1997 & 1.46 & & & 1.27 & 1.31 \\
\hline 1998 & 1.41 & & & 1.34 & 1.31 \\
\hline 1999 & 1.45 & & & 1.29 & 1.23 \\
\hline 2000 & & & & 1.45 & 1.22 \\
\hline
\end{tabular}

Sources: Cited from Guo (2004)

${ }^{1}$ NSB $(1988-2000)$

${ }^{2} \mathrm{Yu}$ and Yuan (1996)

${ }^{3}$ Guo (2000)

${ }^{4}$ Ding (2003)

${ }^{5}$ Guo (2004)

As with any subjective probability distribution based on expert judgement, some experts may disagree with the mean and variance chosen for the distribution and/or the argumentation behind this specific choice. In analogy to dealing with this issue for assumptions concerning the future the resolution of the problem here lies in a continued process of argumentation and scientific evaluation of the arguments. The distribution chosen here can be seen as a benchmark that can be changed in the future should convincing arguments for doing so be presented. However, it needs to be understood that in this probabilistic framework slightly differing views about the mean of the distribution are less critical for the outcome than in the case of deterministic projections using different point estimates for the starting conditions.

As to the future trends in fertility, the uncertainty interval was assumed to open up a bit for the coming decades. Since it is unclear whether the fertility level in China will continue to fall or whether it will recover as a consequence of government policies that aim at stabilising fertility around 1.8-1.9, the assumed $95 \%$ uncertainty range will go to $1.0-2.0$ by 2030 (with linear interpolation 
between 2000 and 2030). The recently released results from the 2005 National One Percent Sample Survey (NBS 2007) with a TFR of 1.33 for 2005 fall well toward the centre of this range, depending on the assessment of the undercount in that survey. After 2030 the range was assumed to shift slightly upwards to 1.2-2.2 in accordance with the substantive considerations discussed in Lutz, Sanderson and Scherbov (2004). In terms of the age pattern of fertility the simplifying assumption was made that it does not vary with the level of fertility and agespecific fertility rates are derived from proportional changes depending on the assumed TFR level.

\subsection{Sex ratio at birth}

Tables 3 and 4 provide different estimates of the sex ratio at birth in 2000, another uncertain and highly controversial demographic variable. Table 3 reflects that the trend of biased sex ratios has become more serious since the mid-1980s. Since we only need the total sex ratio for the projections, we focus on the data given in Table 4. It gives seven different estimates of the sex ratio at birth in 2000 that range from 1.13 to 1.23 . We decided to operationalise this uncertainty range by assuming a normal distribution with $95 \%$ between 1.13 and 1.23 . The new results of the 2005 Sample Survey (NSB 2007) giving a sex ratio at birth of 120.5 also fall well into this range. Over time we assume that by 2030 a normal sex ratio at birth of 1.05 will be reached with linear interpolation between 2000 and 2030 .

The distorted sex ratio at birth is very clearly visible from the asymmetry of the age pyramid in Figure 1. The projection results (see Figure 2) show this asymmetry, particularly for the cohorts born in 1985 and (following our assumptions) in 2030. Since fertility rates are only applied to women, this distorted sex ratio has a dampening effect on population growth.

Table 3:

Historical trends in the sex ratio at birth in China, 1953-2000

\begin{tabular}{lccccc}
\hline Year & Sex Ratio at birth & Year & Sex Ratio at birth & Year & Sex Ratio at birth \\
\hline 1953 & 104.9 & 1973 & 107.3 & 1987 & 111.0 \\
1960 & 110.3 & 1974 & 106.6 & 1988 & 108.1 \\
1961 & 108.8 & 1975 & 106.4 & 1989 & 111.3 \\
1962 & 106.6 & 1976 & 107.4 & 1990 & 114.7 \\
1963 & 107.1 & 1977 & 106.7 & 1991 & 116.1 \\
1964 & 106.6 & 1978 & 105.9 & 1992 & 114.2 \\
1965 & 106.2 & 1979 & 105.8 & 1993 & 114.1 \\
1966 & 112.2 & 1980 & 107.4 & 1994 & 116.3 \\
1967 & 106.6 & 1981 & 107.1 & 1995 & 117.4 \\
1968 & 102.5 & 1982 & 107.2 & 1996 & 118.5 \\
1969 & 104.5 & 1983 & 107.9 & 1997 & 120.4 \\
1970 & 105.9 & 1984 & 108.5 & 1998 & 122.1 \\
1971 & 105.2 & 1985 & 111.4 & 1999 & 122.7 \\
1972 & 107.0 & 1986 & 112.3 & 2000 & 119.9 \\
\hline
\end{tabular}

Sources: Gu and Xu (1994) for 1960-1992; Lu (2003) for 1993-2000. 
Table 4:

Different estimates for the sex ratio at birth in $\mathbf{2 0 0 0}$

\begin{tabular}{lc}
\hline Source & Sex Ratio at Birth \\
\hline Wang (2003) & 113.40 \\
SPFPC and CPDC (2003) & 116.86 \\
NSB (2002b) & 117.79 \\
Ma (2004) & 122.65 \\
Lu (2003) & 119.9 \\
Banister (2002) & 120 \\
Zhang and Cui (2003) & $>=115$ \\
\hline
\end{tabular}

\section{Figure 1}

\section{Probabilistic age pyramid, 2000}

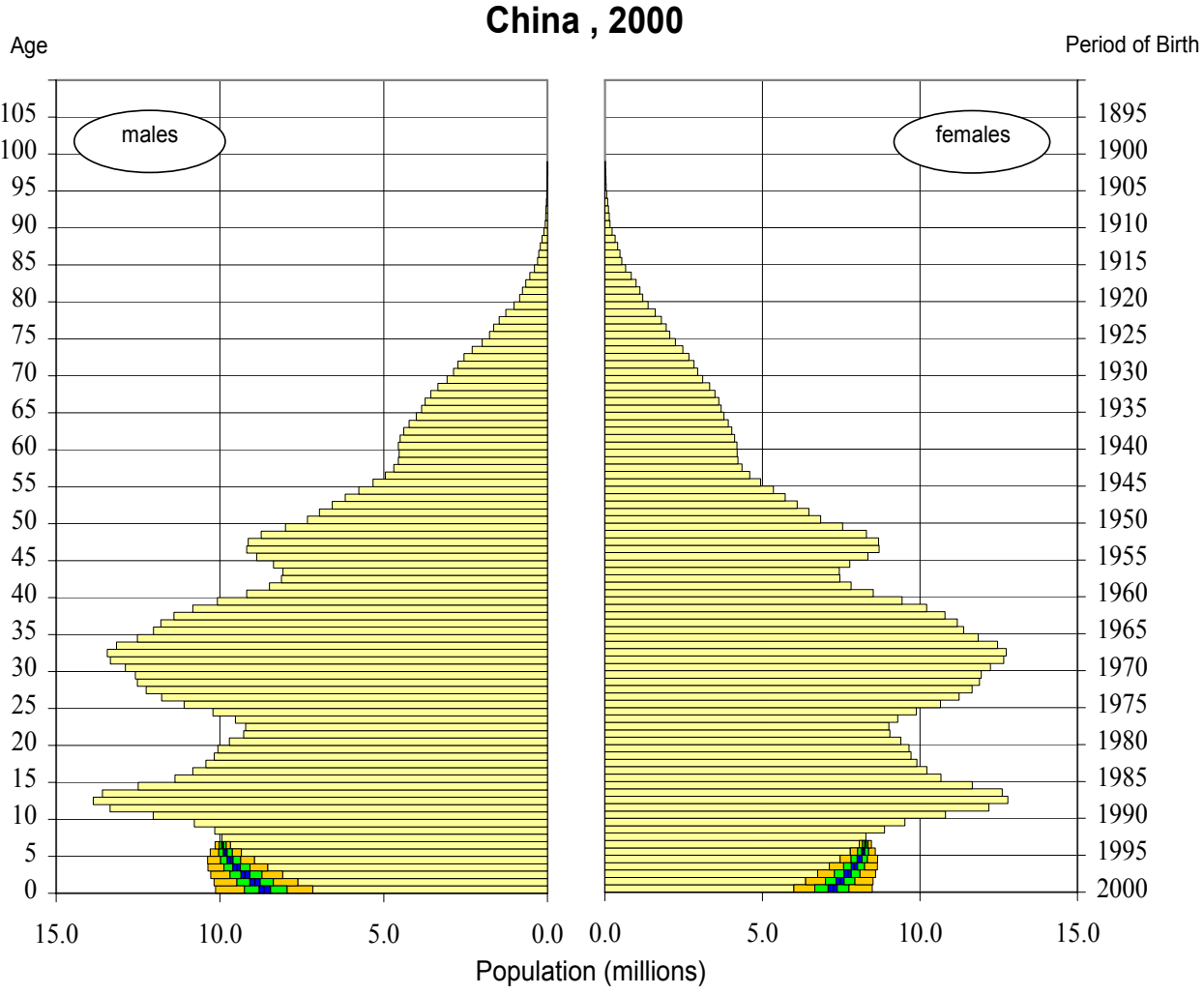

Note: The uncertainty distributions are described in the form of fractiles of the distribution of outcomes from all simulations. In the figures the black area gives the range between the .4 and .6 fractiles, the dark grey area that between .2 and .8 and the light grey that between .025 and .975 , i.e., the 95 per cent interval. 


\subsection{Size of youngest age groups}

The third kind of uncertainty of starting conditions which was considered explicitly here concerns the age structure and in particular the relative size of the youngest age groups. Table 5 provides the age distribution based on the official census count. Again there is reason to assume that it includes significant underreporting of children that corresponds to the underreporting of births in the measurement of recent fertility. This underreporting becomes evident when producing projections of the Chinese population based on the starting year 1990 and when applying alternative fertility rates considered plausible.

Table 5:

Age distribution of the 2000 census (adjustment by Jiang and Ren)

\begin{tabular}{lrrr}
\hline Age & Male & Female & Total \\
\hline $0-4$ & 39080442 & 32330340 & 71410782 \\
$5-9$ & 50803287 & 44105742 & 94909029 \\
$10-14$ & 68852541 & 63165421 & 132017961 \\
$15-19$ & 51910244 & 48709494 & 100619739 \\
$20-24$ & 44167951 & 44101447 & 88269398 \\
$25-29$ & 57358164 & 56362758 & 113720922 \\
$30-34$ & 63871217 & 62751382 & 126622599 \\
$35-39$ & 56371339 & 54871791 & 111243130 \\
$40-44$ & 43225101 & 40999383 & 84224484 \\
$45-49$ & 45995722 & 44185113 & 90180835 \\
$50-54$ & 34357617 & 32420433 & 66778051 \\
$55-59$ & 25405390 & 23864012 & 49269402 \\
$60-64$ & 22783865 & 21047268 & 43831133 \\
$65-69$ & 18515844 & 18251975 & 36767820 \\
$70-74$ & 13059340 & 13791954 & 26851294 \\
$75-79$ & 7541698 & 9210723 & 16752421 \\
$80-84$ & 3409902 & 4890141 & 8300043 \\
$85-89$ & 1090862 & 1992949 & 3083811 \\
$90+$ & 274580 & 702567 & 977147 \\
Total & 648075107 & 617754893 & 1265830000 \\
\hline
\end{tabular}

Note: This adjustment of the raw census data makes the age distribution more consistent by maintaining total population count in the census which was equal to 1.26583 billion.

Source: Jiang and Ren (2005).

There have also been several attempts to correct the age structure of the 2000 census although the number of such efforts was much smaller than the number of different fertility estimates. We decided against systematically studying these correction attempts of the age structure because we would have no direct use of them in our probabilistic population projections. This is due to the necessary consistency between our assumptions on the level of fertility in 2000 and the size of the youngest age group in that year. If we choose a rather high fertility level from our uncertainty distribution of the 2000 TFRs, we also need to choose a size 
of the youngest age group that is comparatively larger because it was produced by these higher fertility rates over the past few years.

In order to deal with this consistency issue between the chosen level of TFR and the size of the youngest age groups, we designed a specific routine that calculates a separate age distribution for the year 2000 for each of the 1,000 separate simulation runs. This routine is based on the assumption that underreporting primarily affects children below school age. It assumes that the number of seven-year-old girls and boys reported in the census is more or less correct (of course, the method can also be applied assuming a higher age at which underreporting of children stops). Based on this assumption, we were able to calculate which level of TFR in 1993 produces the given number of children of that age group. Next, for each simulation run, a TFR value for 2000 was randomly chosen from the specified distribution. Then for each simulation, the following calculations were performed: A linear interpolation was applied between the TFR estimated for 1993 and the one assumed for 2000. The resulting TFRs were then applied to a projection that reproduced the number of births between 1993 and 2000. Applying plausible child mortality rates produced a new age structure for the year 2000. As a result, for each simulation run we have a separate age structure for children that is exactly consistent with the fertility level chosen for the specific run.

Figure 1 shows the resulting uncertainty distribution of the age pyramid of China in 2000. The grey area shows the age-specific uncertainties due to the alternatively estimated age distributions.

\subsection{Projections}

For the projection methodology itself, we chose the same approach as extensively discussed in Lutz et al. (2004). It is a stochastic simulation with annual fluctuations of vital rates within a variance as defined by expert opinion. The trends and the assumed ranges follow the same logic as in Lutz et al. (2004); we do not have room to discuss them here. In short, we carry out a set of 1000 independent cohort component projections from which we draw the fertility and mortality levels for each year randomly from the specified uncertainty distributions using a moving average procedure to assure a certain serial correlation. For fertility a normal distribution was assumed with a mean of 1.5 and $95 \%$ of all cases in the range between 1.0 and 2.0 before 2030 , and after that with a mean of 1.7 and $95 \%$ of all future cases in the range between 1.2 and 2.2. This assumption implies that there is a chance that $5 \%$ will fall outside this range on either side. For mortality the starting life expectancy for 2000 was assumed to be 69.7 years for men and 74.5 years for women. We took this as a point estimate without explicit consideration of uncertainty. For the future, however, we assumed that life expectancy would on average increase by two years per decade with $95 \%$ of the uncertainty distribution falling between an increase of only one 
year and three years per decade. This implies that for 2050 the ranges for life expectancy at birth go from 74.7 to 84.7 for men and from 79.5 to 89.5 for women. We also assumed a closed population, i.e., no net migration gains or losses.

\section{Results}

Figures 2 to 5 show the results of 1,000 simulations, each a separate cohortcomponent projection with the starting conditions as well as fertility, sex ratio at birth and mortality drawn from the uncertainty distribution as described above. The figures present the results in terms of fractiles of the resulting distributions. The white line in the centre gives the median. The black area gives the range between the 0.4 and 0.6 fractiles, the dark grey area that between 0.2 and 0.8 and the light grey that between 0.025 and 0.975 .

Figure 2 shows the probabilistic age pyramid for China in 2050. To the left it lists the single years of age and to the right the corresponding years of birth of the cohort. For all cohorts below age 50, i.e., those born after 2000, the broad band of uncertainty reflects the combination of uncertain fertility in 2000 and uncertain future fertility trends. For the youngest cohorts, this uncertainty range is quite significant with the $95 \%$ interval going from around 2.5 million girls to 7.5 million girls, the difference being a factor of three. For those aged 50-70 in 2050, the uncertainty range is the smallest. This is because these cohorts are already born and the cohort size is roughly known (subject only to the uncertainty about the current age distribution as discussed above) and they have not yet entered the high mortality ages when the uncertainty about future old-age mortality comes to bear. It is also remarkable that as a consequence of the Chinese demographic history, these very large age groups born between 1985 and 1990 are not only the biggest cohorts today, but will also be by far the biggest cohorts in 2050. And as the figure illustrates, there is very little uncertainty about this.

Figure 3 shows the resulting uncertainty distribution for total population size. The median of the distribution shows further growth until reaching a peak of 1.38 billion in 2020-2030 and then starts to slowly decline. In 2050 the median is already down to 1.25 billion. But as can be expected the uncertainty range opens with the passage of time. The upper 0.975 fractile keeps growing until around 2035 , reaching almost 1.5 billion; the lower 0.025 fractile starts to go down in 2015 after having reached a peak of 1.30 billion. The 95\% range in 2050 goes from 1.10 billion to 1.54 billion.

Figure 4 shows the proportion of people below age 15 . Here it is clearly visible that the uncertainty about the size of the youngest age groups today, together with the uncertainty of the current level of fertility, causes quite an unusual distribution up to 2025 after which point the pattern becomes more regular and essentially reflects the uncertainty of future fertility levels. Comparing this figure to the age pyramid (Figure 2), it is evident that the proportion of 
children in the population is less uncertain than the absolute number of children. This is because in the case of a high-fertility trajectory, both the number of children and the total population will be higher.

\section{Figure 2:}

Probabilistic age pyramid, 2050

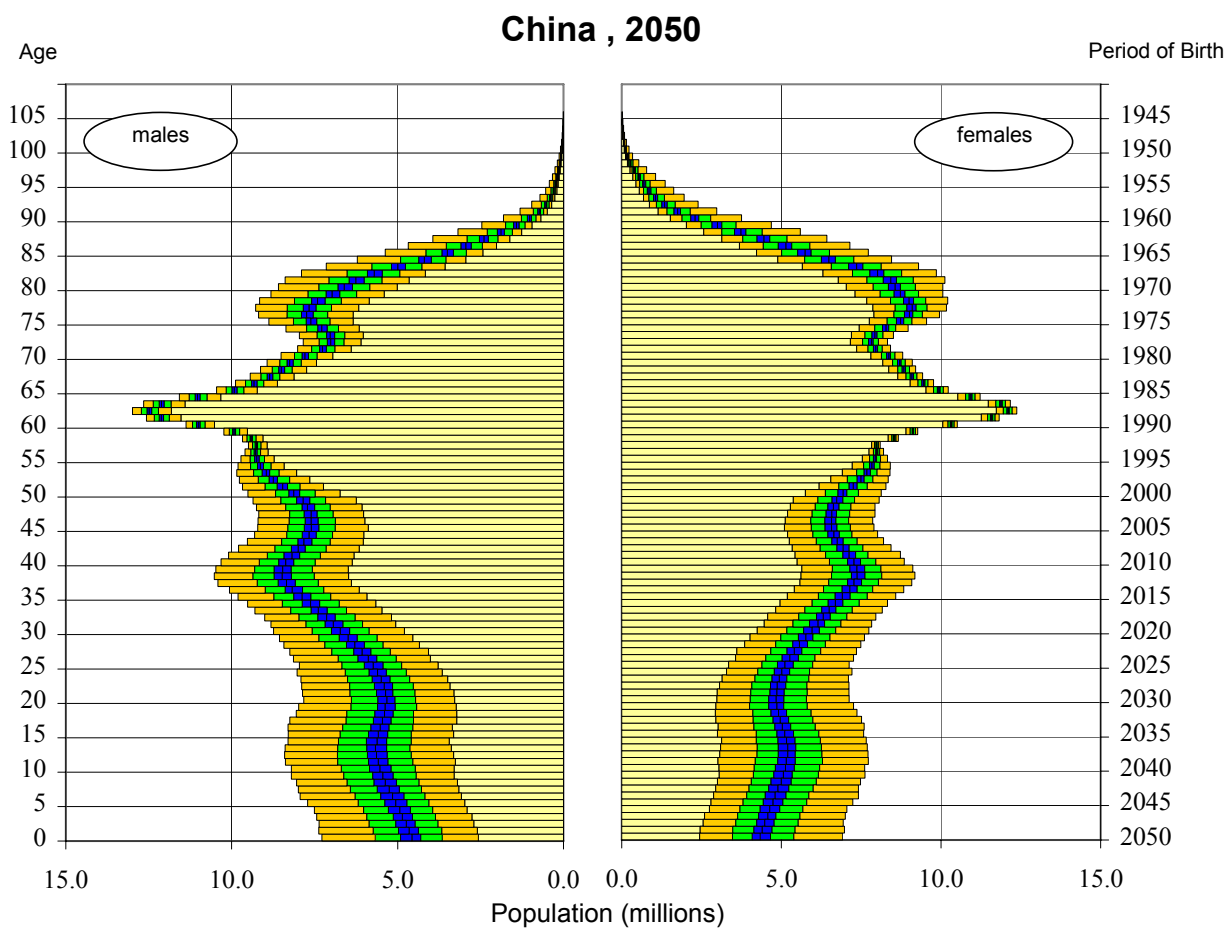

Note: The uncertainty distributions are described in the form of fractiles of the distribution of outcomes from all simulations. In the figures the black area gives the range between the .4 and .6 fractiles, the dark grey area that between .2 and .8 and the light grey that between .025 and .975 , i.e., the 95 per cent interval. 
Figure 3:

Fractiles of distribution for total population, 2000-2100

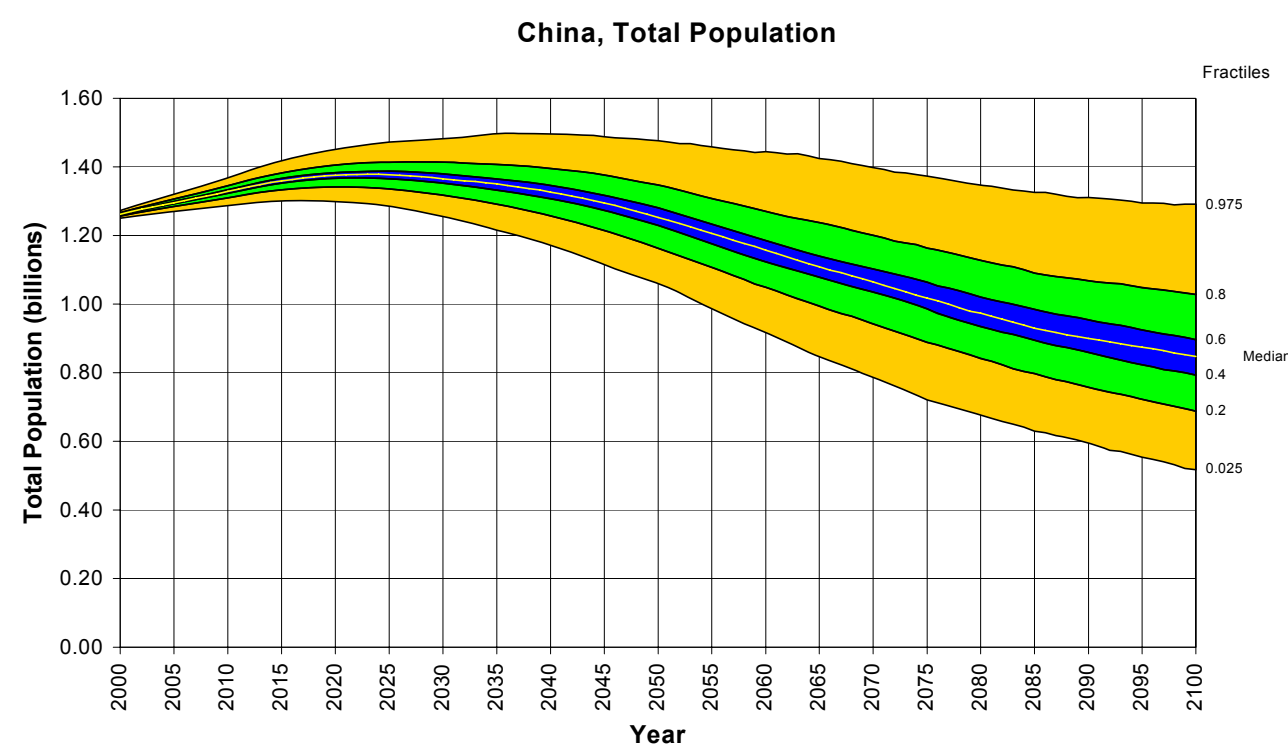

Figure 4:

Fractiles of distribution for proportion below age 15, 2000-2100

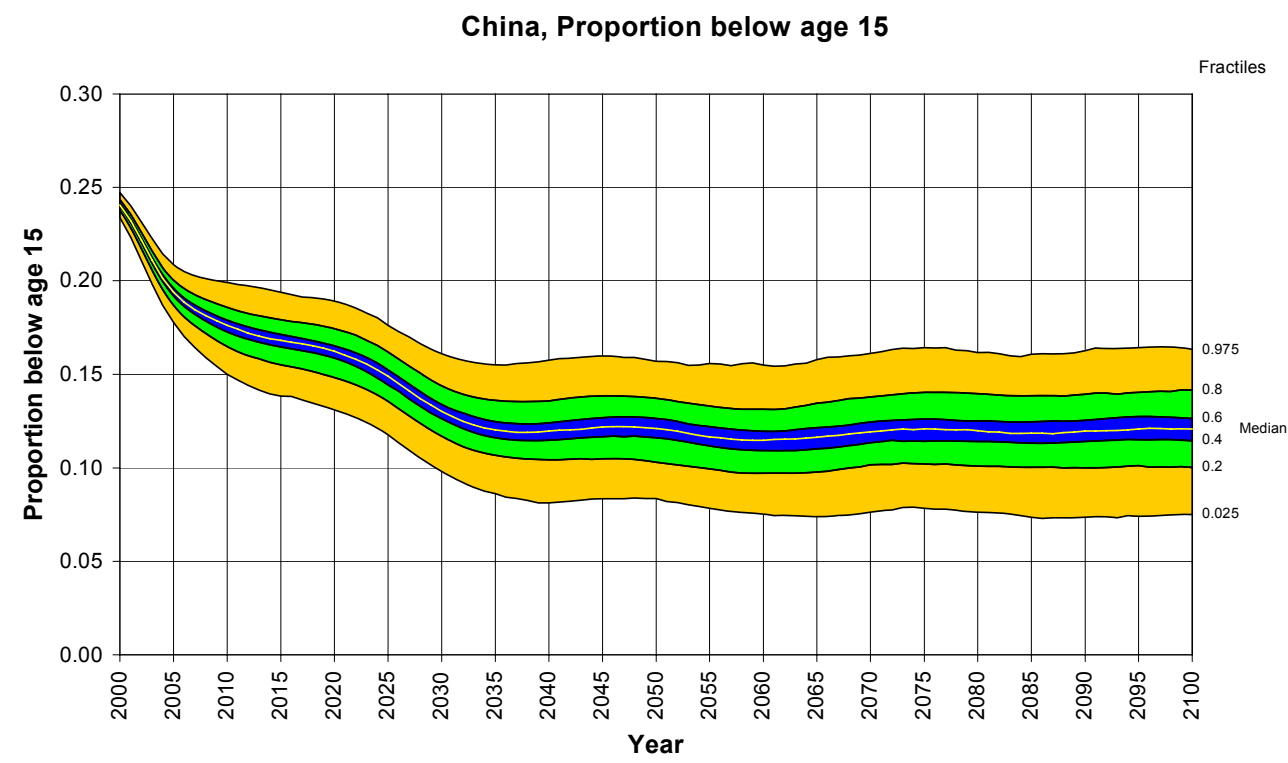

Figure 5 shows the old-age dependency ratio (65+/15-65). This graph shows a most dramatic increase with very little uncertainty until around 2035. The old-age dependency ratio is almost certain to triple in only over three decades. This can be 
said with high confidence as the $95 \%$ uncertainty range is very narrow, a consequence of the fact that a good deal of this increase is already preprogrammed in today's age structure. And even considering the uncertainty about this age structure does not change the pattern significantly. By around 2050 the old-age dependency ratio is expected to increase almost by a factor of five.

\section{Figure 5:}

Fractiles of distribution for old-age dependency ratio, 2000-2100

China, Old-Age Dependency Ratio (65+ / 15-65)

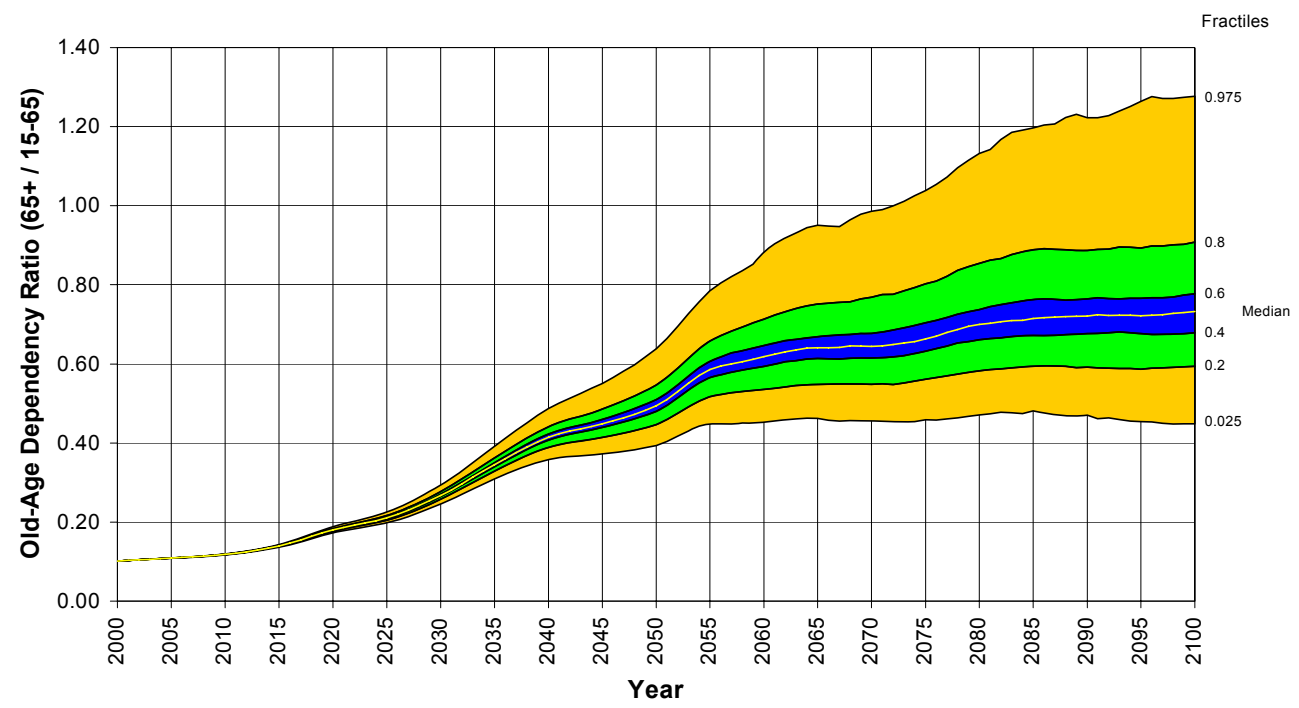

There is also great uncertainty about the possible size of the very old population in China, namely those above age 80 . Currently only around $1 \%$ of the total population of China belong to this age group. This group is expected to gradually increase over the coming few decades to around 3\% in 2030 with very little uncertainty. But over the decades 2030-2050, it is likely to see a marked increase reaching around $10 \%$ by the middle of the century, i.e., ten times its current size. Much of this increase is already embedded in the current age structure of the population due to the strong cohorts born around 1970. Another significant push in the proportion above age 80 is expected before 2070 when it is likely to jump to close to $15 \%$ of the total population because the very big cohorts born in the mid-1980s will reach this high age. Of course, the uncertainty range around this median projection significantly broadens during the second half of the century. Like in most other low-fertility countries in the world, the future course of old-age mortality is highly uncertain. If the proponents of an unabated increase in life expectancy are correct, then China may well have a quarter of its total population above the age of 80 by the end of the century. And even if the "pessimists" were right, this proportion would still increase to between $10 \%$ and $15 \%$ of the population. 


\section{Conclusions}

This paper has demonstrated that over the coming decades, the world's biggest national population will experience some of the most rapid and most massive processes of population ageing in world history. Neither current uncertainties about the level of fertility, the sex ratio and the number of children already born nor the uncertainty about future vital rates significantly weakens this very robust forecast.

When it comes to population size, however, the uncertainties considered do have quite some impact. The projections show that there is about an $80 \%$ chance that by the end of the century, China's population size will again fall below 1 billion, even though over the coming decades we will see further increase due to the momentum caused by a young age structure. Almost certainly (with more than $97.5 \%$ probability) China's population will surpass 1.3 billion over the next few decades. The point at which it will begin to fall greatly depends on the assumptions made about current and future fertility trends as discussed. Our projections show that almost certainly (with a probability of more than $97.5 \%$ ) the population will not reach 1.5 billion. The median shows a peak of 1.377 around 2025. After that, the population starts to decline with the median in 2100 showing 850 million people, almost $40 \%$ below its peak level.

China is currently benefiting from a very low total dependency ratio. There are few children and not yet many elderly persons. This demographic window of opportunity, which is also one factor behind the currently very high economic growth rates, will close in the foreseeable future. Our projections show that there is no uncertainty that the old-age dependency burden will dramatically increase over the coming decades. This will pose serious challenges for China's social and economic structure and needs to be addressed soon because such institutional adjustments take time.

This expected population ageing and shrinking will also have significant impacts on the projected global trends. Contrary to earlier world population projections, fertility is now being assumed to lie in the 1.4-1.5 range around the year 2000 rather than in the 1.8-1.9 range as previously assumed, which will result in lower projected global population sizes. In its recent long range projections (still based on a 2000 TFR of 1.8) the UN Population Division projects a population for China of 1.395 billion in 2050 and 1.181 billion in 2100 (UN 2004). In its 2004 fertility data sheet, the UN gives a TFR estimate of 1.4 for 2001 (UN 2005). This has not yet been implemented into their published projections. Based on these more recent assumptions, our projections presented here show that the population of China is likely to be 334 million less in 2100 than the number given in the UN long-range projections. This implies that world population size would have to be corrected downwards by 0.33 billion in 2100 .

This paper has also shown that existing methods of expert-based probabilistic forecasting can readily be expanded to include uncertainty about the current demographic conditions. They provide a comprehensive tool to jointly consider 
all sources of uncertainty that can influence the evolution of population age and structure over time. To the user they can provide an easy to understand summary of all expert knowledge and expert judgement on what can be said about likely future population patterns and the degree of confidence with which such information should be seen.

\section{Acknowledgements}

The authors would like to acknowledge the support given to Qiang Ren and Xiaoying Zheng by the National Natural Science Foundation of China (No. 70373011) as well as the programs 211 and 985 of Peking University.

\section{References}

Alho, J. 1997. "Scenarios, Uncertainty and Conditional Forecasts of the World Population." Journal of the Royal Statistical Society Series A 160(1):71-85.

Banister, J. 2002. "The Dearth of Girls in China Today: Origins, Geography, and Comparative Perspectives." Research Report, September 28, 2002. Beijing: UNFPA China.

Cai, Y. 2006. "An Assessment of China's Fertility Level Using the Variable-r Method." CSDE Working Paper No.05-06, Center for Studies in Demography and Ecology, University of Washington.

CPDRC. 2003. "Studies on Fertility Level Since the 1990s." Unpublished Report. Beijing: China Population and Development Research Center (CPDRC).

Ding, J. 2003. "Analysis About the Impact of Changes in Fertility Pattern on Fertility Level for China Between 1991-2002." Chinese Journal of Population Research 27(2):55-60.

ESCAP. 2002. Population Data Sheet. Bangkok, Thailand: United Nations Economic and Social Commission for Asia and the Pacific (ESCAP), Population and Rural and Urban Development Division.

Gu, B. and Y. Xu. 1994. "A Roundup of the Sex Ratio at Birth in China." Chinese Journal of Population Science 3:41-48.

Guo, Z., and Chen, W. 2007. "Below replacement level fertility in mainland China." In: Z. Zhao and Z. Guo (eds.) Transition and Challenge: China's Population at the Beginning of the 21st Century. Oxford University Press.

Guo, Z. 2000. "Lifetime Fertility of Chinese Women: A Look at the Recent Period Fertility Behavior." Chinese Journal of Population Research 24(1):7-18.

Guo, Z. 2003. "Study for Fertility of China in the 1990s." Paper presented at the International Workshop on China's Population Change at the Beginning of the 21st Century, Canberra, Australia, December 10-12, 2003.

Guo, Z. 2004. "Fertility in China in the 1990s." Chinese Journal of Population Research 28(2):10-19.

Jiang, L. and Q. Ren. 2005. "The Projection of Population, Households and Housing Demand in China." Chinese Journal of Market and Demographic Analysis 11(2):20-29. 
Keilman, N. 1999. "How Accurate are the United Nations World Population Projections?" In: W. Lutz, J.W. Vaupel, and D.A. Ahlburg (eds.) Frontiers of Population Forecasting. A Supplement to Vol. 24, 1998, Population and Development Review. New York: The Population Council, pp. 15-41.

Lee, R.D. 1993. "Modeling and Forecasting the Time Series of US Fertility: Age Patterns, Range, and Ultimate Level." International Journal of Forecasting 9: 187-202.

Lee, R.D. 1999. "Probabilistic Approaches to Population Forecasting." In: W. Lutz, J.W. Vaupel, and D.A. Ahlburg (eds.) Frontiers of Population Forecasting. A Supplement to Vol. 24, 1998, Population and Development Review. New York: The Population Council, pp. 156-190.

Lee, R.D. and S. Tuljapurkar. 1994. "Stochastic Population Forecasts for the United States: Beyond High, Medium, and Low." Journal of the American Statistical Association 89(428): 1175-1189.

Liang, Z. 2003. "An Alternate Estimation of China's Total Population and Women's Fertility in 2000." Chinese Journal of Population Science 6: 9-16.

Lu, H. 2003. "Studies on Recent Rising in Sex Ratio at Birth in China." Paper presented at the Symposium of Population and Development of Constructing a Comprehensive Well-off Society, Changchun, PR China, September 25, 2003.

Lutz, W. and J. Goldstein, Guest Editors. 2004. Special issue on "How to Deal with Uncertainty in Population Forecasting?" International Statistical Review 72(12):1-106, 157-208.

Lutz, W., W. Sanderson, and S. Scherbov. 1997. "Doubling of World Population Unlikely." Nature 387:803-805.

Lutz, W., W. Sanderson, and S. Scherbov. 1999. "Expert-Based Probabilistic Population Projections." In: W. Lutz, J.W. Vaupel, and D.A. Ahlburg (eds.) Frontiers of Population Forecasting. A Supplement to Vol. 24, 1998, Population and Development Review. New York: The Population Council, pp. 139-155

Lutz, W., W. Sanderson, and S. Scherbov (Eds.) 2004. The End of World Population Growth in the 21st Century: New Challenges for Human Capital Formation and Sustainable Development. London: Earthscan.

Lutz, W., J.W. Vaupel, and D.A. Ahlburg. (Eds.) 1999. Frontiers of Population Forecasting. A Supplement to Vol. 24, 1998, Population and Development Review. New York: The Population Council.

Ma, Y. 2004. "Sex Ratio at Birth in China and the Cost of Low Fertility Reconsidered." Chinese Journal of Population Science 1: 2-13.

National Research Council. 2000. Beyond Six Billion: Forecasting the World's Population. Panel on Population Projections. John Bongaarts and Rodolfo A. Bulatao (eds.) Committee on Population, Commission on Behavioral and Social Sciences and Education. Washington, DC: National Academy Press.

NSB (National Statistics Bureau). 1988-2000. China Population Statistics Yearbook, 1988-2000. Beijing: China Statistics Press.

NSB (National Statistics Bureau). 2002a. 2001 China Population. Department of Population, Social, Science and Technology Statistics. Beijing: China Statistics Press.

NSB (National Statistics Bureau). 2002b. Tabulation on the 2000 Population Census of the People's Republic of China. Population Census Office under the State Council, Department of Population, Social, Science and Technology Statistics. Beijing: China Statistics Press.

NSB (National Statistics Bureau). 2007. Tabulation of the 2005 National One Percent Population Sample Survey. Population Census Office under the State Council, 
Department of Population, Social, Science and Technology Statistics. Beijing: China Statistics Press

Retherford, R., Choe, M.K., Chen, J. Li, X., and Cui H. 2005. "Fertility in China: How Much Has It Really Declined?" Population and Development Review 31 (1): 57-84.

SFPC. 2001. Communiqué on Major Figures of Family Planning, No. 1" Beijing: State Family Planning Committee (SFPC).

SFPC. 2002. Communiqué on 2001 National Family Planning/Reproductive Health Survey. Beijing: State Family Planning Committee (SFPC).

Scharping, T. 2005. "Chinese fertility trends 1979-2000: A comparative analysis of birth numbers and school data." Chinese Journal of Population Research 29(4): 1-12.

SPFPC and CPDC. 2003. "Handbook of Common Data for Population and Family Planning." Unpublished Report. Beijing: State Population and Family Planning Committee (SPFPC) and China Population and Development Center (CPDC).

UN. 2004. World Population to 2300. UN Publication ST/ESA/SER.A/236. New York: United Nations, Department of Economic and Social Affairs, Population Division.

UN. 2005. World Fertility Patterns 2004. UN Publication ST/ESA/SER.A/238. New York: United Nations, Department of Economic and Social Affairs, Population Division.

U.S. Census Bureau. 2004. International Data Base. Data released 4-30-2004.

Wang, J. 2003. "Estimation of TFR Level With Changing Childbearing Pattern in China: 1990-2000." Chinese Journal of Population Science 4: 32-38.

$\mathrm{Yu}$, X. 2002. "Estimation of Size and Structure of Chinese Population by the Fifth National Census." Chinese Journal of Population Research 26(3): 9-15.

Yu, J. and H. Yuan. 1996. “Analysis on Chinese Women's Fertility in Recent Years.” In: Z. Jiang (ed.) The Proceedings of 1992 Fertility Sampling Survey in China. Beijing: China Population Publishing House, pp. 21-34

Yuan, J., H. Yu, X. Li, Q. Xu, and T. Jiang. 2003. "Estimation of Fertility and Population Projection in China." Chinese Journal of Population Science 1: 15-21.

Zhai, Z. 2003. "Building a Comprehensive Well-Off Society and Solving Population Problems in an All-Round Manner." Chinese Journal of Population Research 27(1): $1-4$.

Zhang, G and Z. Zhao. 2006. "Re-examining China's fertility puzzle: Data collection and quality over the last two decades." Population and Development Review 32 (2): 293-321.

Zhang, G. 2004. "Very Low Fertility in China in the 1990s: An Illusion of Birth Underreporting?" Paper presented at the Annual Meeting of the Population Association of America (PAA), Boston, MA, April 1-3, 2004.

Zhang, W. and H. Cui. 2003. "Estimation of Accuracy of 2000 National Population Census Data." Chinese Journal of Population Research 27(4): 25-35.

Zhang, W., G. Xu, H. Yu, and H. Cui. 2004. "Forecasting of China Population Change." In: X. Tian and G. Wang (eds.) Population and Development of Constructing a Comprehensive Well-off Society. Beijing: China Population Publishing House, pp. 91-128. 


\section{APPENDIX TABLES}

\section{China, life expectancy}

\begin{tabular}{|c|c|c|c|c|c|c|c|c|c|c|c|c|c|}
\hline Indic & iterval & Sex & 2004 & 2010 & 2020 & 2030 & 2040 & 2050 & 2060 & 2070 & 2080 & 2090 & 2100 \\
\hline$\overline{\mathrm{e} 0}$ & 025 & tal & 2.269 & 72.810 & 73.717 & 74.543 & 75.250 & 75.868 & 76.683 & 77.982 & 78.245 & 79.670 & 79.956 \\
\hline $\mathrm{e} 0$ & 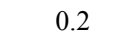 & Total & 72.524 & 73.448 & 74.891 & 76.364 & 77.641 & 88 & 80.818 & 64 & 89 & 85.744 & 7.041 \\
\hline $\mathrm{e} 0$ & .4 & Total & 72.657 & 73.799 & 75.619 & 77.445 & 79.259 & 81.104 & 82.939 & 84.739 & 86.610 & 88.792 & 90.572 \\
\hline $\mathrm{e} 0$ & 0.6 & Total & 72.779 & 74.084 & 76.262 & 78.417 & 80.488 & 82.438 & 84.637 & 86.873 & 88.887 & 91.163 & 93.473 \\
\hline $\mathrm{e} 0$ & 8 & 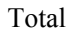 & 72.934 & 74 & 76 & 79 & 8 & 2 & 3 & 6 & 0 & 94.735 & 97.272 \\
\hline $\mathrm{e} 0$ & .975 & Tota & 73.183 & 75.079 & 78.385 & 81.413 & 84.980 & 87.800 & 90.821 & 94.082 & 97. & 101 & 103.471 \\
\hline $\mathrm{e} 0$ & Mean & Tota & 72.721 & 73.939 & 75.962 & 77.946 & 79.883 & 81.760 & 83.782 & 85.791 & 87.842 & 90.144 & 92.075 \\
\hline $\mathrm{e} 0$ & Median & Tot: & 72.716 & 73.944 & 75.956 & 77.907 & 79.847 & 81.766 & 83.777 & 85.857 & 87.670 & 90.144 & 92.018 \\
\hline $\mathrm{e} 0$ & STDev & Total & 0.238 & 0.587 & 1.207 & 1.834 & 2.513 & 3.032 & 3.622 & 4.137 & 4.814 & 5.459 & 6.032 \\
\hline
\end{tabular}

China, proportion below age 15

\begin{tabular}{|c|c|c|c|c|c|c|c|c|c|c|c|c|c|}
\hline Indi & terval & Sex & 2004 & 2010 & 2020 & 2030 & 2040 & 2050 & 2060 & 2070 & 2080 & 2090 & 2100 \\
\hline 15 & 025 & 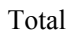 & 187 & 50 & 21 & 008 & 0.081 & 24 & 075 & 0.076 & 0.076 & 0.074 & .075 \\
\hline$P 1$ & 0.2 & Total & 5 & 65 & 8 & 17 & 4 & 3 & 97 & 2 & 1 & 0 & 100 \\
\hline Prop 0-15 & 0.4 & Total & 0.200 & 0.173 & 0.159 & 0.126 & 0.115 & 0.116 & 0.109 & 0.113 & 0.114 & 0.114 & 0.114 \\
\hline Prop 0-15 & 0.6 & (2) & 0.203 & 0.179 & 0.165 & 0.134 & 0.124 & 0.126 & 0.119 & 0.124 & 0.125 & 0.125 & 0.126 \\
\hline $0-12$ & 0.0 & & 0.201 & 0.186 & 0.174 & 0.144 & 0.130 & 0.137 & 0.131 & 38 & 0.140 & 0.139 & 0.142 \\
\hline Prol & .975 & 100 & 0.215 & 0.199 & 0.189 & 0.161 & 0.158 & 0.157 & 0.155 & 0.161 & 0.162 & 0.163 & 0.163 \\
\hline 15 & 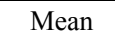 & 1 & 0.201 & 75 & 61 & 0 . & 0. & 0 . & 0 . & 0 . & 20 & 19 & 0.121 \\
\hline $0-15$ & Median & Tot & 0.201 & 0.176 & 0.162 & 0.130 & 0.120 & 0.121 & 0.115 & 0.1 & 0.120 & 0.120 & 0.121 \\
\hline Prop 0-15 & STDev & Total & 0.007 & 0.012 & 0.015 & 0.016 & 0.019 & 0.020 & 0.020 & 0.022 & 0.022 & 0.023 & 0.023 \\
\hline
\end{tabular}

\section{China, proportion 15-65}

\begin{tabular}{|c|c|c|c|c|c|c|c|c|c|c|c|c|c|}
\hline Indicator & Interval & Sex & 2004 & 2010 & 2020 & 2030 & 2040 & 2050 & 2060 & 2070 & 2080 & 2090 & 2100 \\
\hline rop $15-65$ & 0.025 & Total & 0.709 & 0.716 & 0.689 & 0.666 & 599 & 0.551 & 485 & 0.459 & 0.427 & 0.411 & 0.403 \\
\hline rop $15-65$ & 0.2 & Total & 0.716 & 0.728 & 0.701 & 0.678 & 0.611 & 0.572 & 0.523 & 0.504 & 0.482 & 0.471 & 0.468 \\
\hline Prop $15-65$ & 0.4 & Cotal & 0.719 & 0.735 & 0.707 & 0.683 & 0.618 & 0.583 & 0.539 & 0.526 & 0.507 & 0.499 & 0.496 \\
\hline-65 & 0.6 & & 3 & 0 & 3 & 9 & 625 & 93 & 54 & 542 & .527 & 22 & .521 \\
\hline Prop 15-65 & 0.8 & Tot & & 0.747 & & & & & 0.569 & 0.562 & & 0.545 & 0.543 \\
\hline Prop 15-65 & 0.975 & Total & 0.734 & 0.760 & 0.733 & 0.707 & 0.646 & 0.621 & 0.595 & 0.591 & 0.585 & 0.586 & 0.585 \\
\hline נים 18 & & 10 & 0.12 s & 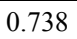 & 0.1 & .0 & .622 & 7 & 0.545 & 0.532 & - & .507 & 0.505 \\
\hline Prop 15-65 & Median & Total & 0.721 & 0.737 & 0.710 & 0.686 & 0.621 & 0.588 & 0.546 & 0.534 & 0.516 & 0.512 & 0.508 \\
\hline Prop 15-65 & STDev & Total & 0.006 & 0.011 & 0.012 & 0.011 & 0.012 & 0.018 & 0.028 & 0.034 & 0.040 & 0.045 & 0.047 \\
\hline
\end{tabular}


China, proportion above age 80

\begin{tabular}{|c|c|c|c|c|c|c|c|c|c|c|c|c|c|}
\hline Indicator & Interval & Sex & 2004 & 2010 & 2020 & 2030 & 2040 & 2050 & 2060 & 2070 & 2080 & 2090 & 2100 \\
\hline Prop 80+ & 0.025 & Total & 0.011 & 0.015 & 0.019 & 0.028 & 0.042 & 0.067 & 0.073 & 0.093 & 0.091 & 0.088 & 0.097 \\
\hline Prop 80+ & 0.2 & Total & 0.012 & 0.015 & 0.020 & 0.030 & 0.047 & 0.080 & 0.090 & 0.119 & 0.121 & 0.124 & 0.147 \\
\hline Prop 80+ & 0.4 & Total & 0.012 & 0.015 & 0.021 & 0.031 & 0.051 & 0.088 & 0.102 & 0.137 & 0.144 & 0.150 & 0.175 \\
\hline Prop 80+ & 0.6 & Total & 0.012 & 0.015 & 0.021 & 0.032 & 0.054 & 0.095 & 0.113 & 0.154 & 0.163 & 0.173 & 205 \\
\hline Prop 80+ & 0.8 & Total & 0.012 & 0.015 & 0.022 & 0.034 & 0.058 & 0.104 & 0.128 & 0.175 & 0.195 & 0.208 & 0.241 \\
\hline Prop 80+ & 0.975 & Total & 0.012 & 0.016 & 0.023 & 0.038 & 0.067 & 0.125 & 0.162 & 0.225 & 0.260 & 0.289 & 0.327 \\
\hline Prop 80+ & Mean & Total & 0.012 & 0.015 & 0.021 & 0.032 & 0.053 & 0.093 & 0.110 & 0.148 & 0.159 & 0.168 & 0.195 \\
\hline Prop 80+ & Median & Total & 0.012 & 0.015 & 0.021 & 0.032 & 0.052 & 0.092 & 0.107 & 0.144 & 0.154 & 0.161 & 0.190 \\
\hline Prop 80+ & STDev & Total & 0.000 & 0.000 & 0.001 & 0.003 & 0.006 & 0.014 & 0.023 & 0.034 & 0.044 & 0.051 & 0.058 \\
\hline
\end{tabular}

\section{China, proportion above age 65}

\begin{tabular}{|c|c|c|c|c|c|c|c|c|c|c|c|c|c|}
\hline Indicator & Interval & Sex & 2004 & 2010 & 2020 & 2030 & 2040 & 2050 & 2060 & 2070 & 2080 & 2090 & 2100 \\
\hline Prop $65+$ & 0.025 & Total & 0.076 & 0.084 & 0.121 & 0.166 & 0.224 & 0.240 & 0.264 & 0.265 & 0.272 & 0.271 & 0.261 \\
\hline Prop 65+ & 0.2 & Total & 0.077 & 0.086 & 0.125 & 0.176 & 0.244 & 0.269 & 0.305 & 0.307 & 0.319 & 0.320 & 0.322 \\
\hline Prop 65+ & 0.4 & Total & 0.077 & 0.087 & 0.127 & 0.181 & 0.254 & 0.284 & 0.329 & 0.334 & 0.348 & 0.355 & 0.354 \\
\hline Prop 65+ & 0.6 & Total & 0.078 & 0.087 & 0.129 & 0.185 & 0.262 & 0.297 & 0.349 & 0.358 & 0.377 & 84 & 0.386 \\
\hline Prop $65+$ & 0.8 & Total & 0.078 & 0.088 & 0.132 & 0.191 & 0.273 & 0.315 & 0.374 & 0.387 & 0.412 & 0.419 & 0.425 \\
\hline Prop $65+$ & 0.975 & Total & 0.079 & 0.090 & 0.136 & 0.203 & 0.298 & 0.354 & 0.430 & 0.450 & 0.482 & 0.507 & 0.513 \\
\hline Prop 65+ & Mean & Total & 0.078 & 0.087 & 0.128 & 0.184 & 0.259 & 0.292 & 0.341 & 0.349 & 0.366 & 0.373 & 0.374 \\
\hline Prop 65+ & Median & Total & 0.078 & 0.087 & 0.128 & 0.183 & 0.258 & 0.291 & 0.338 & 0.345 & 0.361 & 0.368 & 0.372 \\
\hline Prop 65+ & STDev & Total & 0.001 & 0.001 & 0.004 & 0.009 & 0.018 & 0.028 & 0.041 & 0.048 & 0.055 & 0.060 & 0.063 \\
\hline
\end{tabular}

China, old-age dependency ratio (OADR), ratio 65+/(15-65)

\begin{tabular}{|c|c|c|c|c|c|c|c|c|c|c|c|c|c|}
\hline Indicator & Interval & Sex & 2004 & 2010 & 2020 & 2030 & 2040 & 2050 & 2060 & 2070 & 2080 & 2090 & 2100 \\
\hline OADR & 0.025 & Total & 0.107 & 0.117 & 0.173 & 0.245 & 0.359 & 0.393 & 0.453 & 0.455 & 0.471 & 0.470 & 0.449 \\
\hline OADR & 0.2 & Total & 0.107 & 0.118 & 0.177 & 0.257 & 0.389 & 0.447 & 0.536 & 0.549 & 0.583 & 0.592 & 0.594 \\
\hline OADR & 0.4 & Total & 0.107 & 0.118 & 0.179 & 0.264 & 0.408 & 0.480 & 0.594 & 0.615 & 0.662 & 0.677 & 0.679 \\
\hline OADR & 0.6 & Total & 0.108 & 0.118 & 0.181 & 0.270 & 0.423 & 0.510 & 0.646 & 0.677 & 0.738 & 0.764 & 0.778 \\
\hline OADR & 0.8 & Total & 0.108 & 0.119 & 0.184 & 0.277 & 0.441 & 0.547 & 0.713 & 0.769 & 0.854 & 0.887 & 0.908 \\
\hline OADR & 0.975 & Total & 0.108 & 0.119 & 0.188 & 0.293 & 0.487 & 0.638 & 0.882 & 0.986 & 1.133 & 1.223 & 1.277 \\
\hline OADR & Mean & Total & 0.108 & 0.118 & 0.180 & 0.267 & 0.416 & 0.498 & 0.630 & 0.664 & 0.726 & 0.752 & 0.760 \\
\hline OADR & Median & Total & 0.108 & 0.118 & 0.180 & 0.267 & 0.414 & 0.495 & 0.619 & 0.644 & 0.700 & 0.721 & 0.732 \\
\hline OADR & STDev & Total & 0.000 & 0.001 & 0.004 & 0.012 & 0.032 & 0.059 & 0.108 & 0.135 & 0.170 & 0.196 & 0.206 \\
\hline
\end{tabular}


China, total population (million)

\begin{tabular}{|c|c|c|c|c|c|c|c|c|c|c|c|c|c|}
\hline Indicator & nterval & Sex & 2004 & 2010 & 2020 & 2030 & 2040 & 2050 & 2060 & 2070 & 2080 & 2090 & 2100 \\
\hline opulation & 0.025 & tal & 266 & 287 & .299 & 1.255 & 1.172 & 1.060 & 0.917 & 0.787 & 0.676 & 0.594 & 0.517 \\
\hline opulation & 0 & Vtal & 279 & 1.309 & 1.342 & 1.317 & 258 & 1.163 & 9 & 0.943 & 841 & 758 & .688 \\
\hline Population & 0.4 & otal & 1.286 & 1.323 & 1.366 & 1.352 & 1.307 & 1.230 & 1.123 & 1.035 & 0.934 & 0.859 & 0.793 \\
\hline opulation & 0.6 & Total & 2 & 1.333 & 1.383 & 1.380 & 1.347 & 1.280 & 1.185 & 1.102 & 1.021 & 0.955 & 0.896 \\
\hline$n$ & 0 & Total & (3) & 1 & 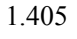 & 4 & 6 & 7 & 1 & 1 & 27 & 67 & 1.028 \\
\hline on & 0.975 & Total & 1.311 & 1.368 & 1.451 & 1.482 & 1.495 & 1.476 & 1.444 & 1.398 & 1.347 & 1.311 & 1.292 \\
\hline n & 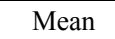 & Total & 1.289 & 1.328 & 1.374 & 1.366 & 1.329 & 1.257 & 1.161 & 1.073 & 0.987 & 0.917 & 0.864 \\
\hline opulation & Median & Tot & 1.289 & 1.328 & 1.375 & 1.366 & 1.326 & 1.252 & 1.157 & 1.064 & 0.973 & 0.900 & 0.847 \\
\hline Population & STDev & Total & 0.011 & 0.021 & 0.038 & 0.058 & 0.082 & 0.107 & 0.130 & 0.152 & 0.171 & 0.187 & 0.199 \\
\hline
\end{tabular}

